\title{
ORAL HEALTH STATUS AND TREATMENT NEEDS AMONG 12 AND 15-YEAR-OLD GOVERNMENT AND PRIVATE SCHOOL CHILDREN IN RUPANDEHI DISTRICT (BHAIRAHAWA) NEPAL
}

Halwai $\mathrm{HK}^{1}$, Bhat $\mathrm{PK}^{2}$, Shekhar $\mathrm{M}^{3}$, Yadav B

\begin{abstract}
INTRODUCTION : Good oral health is important and have major impact on peoples daily lives and activities. This study was conducted to assess dental caries, periodontal health, and malocclusion of school children aged 12 and 15 years and to compare them in government and private schools.
\end{abstract}

MATERIAL AND METHODS: A cross-sectional study of 12- and 15-year-old children in government and private schools was conducted in Rupendehi (Bhairahawa) Nepal. A sample of 1011 school children (both males and females) was selected by a two-stage cluster sampling method. Clinical recordings of dental caries and malocclusion were done according to World Health Organization diagnostic criteria 1997. Periodontal health was assessed by Community Periodontal Index of Treatment Needs index. The data collected was analyzed by SPSS versons 13 . The statistical tests used were $t$-test and Chi-square tests.

RESULTS: The prevalence of dental caries was $32.6 \%$ and $42.2 \%$ at 12 and 15 years of age, respectively. At 12 years of age, the mean decayed, missing, filled teeth were $0.62 \pm 1.42$ and it was $1.06 \pm 2.93$ at 15 years of age. Females had higher level of caries than males at both the ages. At both ages, mean of decayed teeth was statistically higher in government schools as compared with private schools. Children in government schools had significantly less number of mean filled teeth at both ages as compared with private schools. The healthy component of gingiva was present in higher percentage of children in private schools as compared with government schools at both the age groups. The prevalence of malocclusion among the 12 -year-old (58.1\%) was more as compared with that among the 15 -year-old (53.5\%).

CONCLUSION: The caries experience of 12 and 15 years old children was low but the prevalence of gingivitis and malocclusion was quite high. Effective oral health promotion strategies need to be implemented to improve the oral health of school children further in Rupendehi District, Bhairahawa, Nepal.

KEYWORDS: Dental Caries, Malocclusion

1 Associate Professor, Department of Orthodontics \& Dentofacial Orthopaedics, UCMS College of Dental Surgery, Bhairahawa, Nepal

2. Professor and Head of the Department, Department of Public Health Dentistry, Rajarajeswari Dental college and Hospital Bangalore

3. Assistant Professor, Department of Communinity Dentistry,UCMS College of Dental Surgery, Bhairahawa, Nepal

4. Registrar, Departmant of Oral and Maxillofacial Surgery, UCMS College of Dental Surgery, Bhairahawa, Nepal

\author{
For Correspondence \\ Dr. Hemant Kumar Halwai \\ Associate Professor, \\ Department of Orthodontics \& Dentofacial Orthopedics, \\ UCMS College of Dental Surgery \\ Bhairahawa, Nepal \\ E-mail: drhemanthalway@gmail.com
}




\section{INTRODUCTION}

Good oral health is important because the experience of pain, problems with eating, chewing, smiling, and communication due to missing, discolored, or damaged teeth have a major impact on people's daily lives and well-being. Furthermore, oral diseases restrict activities at school, at work, and at home causing millions of school and work hours to be lost each year throughout the world. ${ }^{1}$ Children who suffer from poor oral health are 12 times more likely to have more restricted activity days including missing school than those who do not. ${ }^{2}$ Historically, most important global burdens of the oral health are dental caries and periodontal diseases.

As dental caries is the most common dental disease with high prevalence, it is crucial to control the disease process by assessing and rendering the treatment required along with spreading awareness regarding its prevention. But for developing appropriate preventive approaches, anticipating utilization patterns, and planning effectively for organization and financing of dental resources, the knowledge of oral health status and treatment needs of populations with different characteristics is important.

The schools remain an important setting, offering an efficient and effective way to reach children worldwide and, through them, families and community members. School age is an influential stage in people's life when lifelong sustainable oral health related behaviors, as well as beliefs and attitudes, are being developed. Children are particularly receptive during this period and the earlier the habits are established, the longer lasting the impact. Moreover, the messages can be reinforced regularly throughout the school years. ${ }^{3}$

Various studies have been conducted in different parts of our country, but the literature is very scant for cross comparison in terms of caries status and treatment needs as well as the periodontal status of school children in Nepal. As there are no earlier studies on oral health status of school going children aged 12 and 15 years in, the present study was conducted with the following objectives:

- To assess the dental caries, periodontal health, and malocclusion of school children aged 12 and 15 years of age

- To compare the oral health status and treatment needs in government and private schools

- To establish a reliable baseline data for development of national/regional oral health programs.

\section{Materials and Methods}

A cross-sectional epidemiologic study was conducted among the school-going children aged 12 and 15 years. A pilot study was conducted by randomly selecting one government and one private school from the available list of schools, obtained from the district Education officer. Results from this pilot study showed the prevalence of dental caries was $23.4 \%$. The sample size was calculated by taking this prevalence rate and computed using the Epi Info, Version 6 statistical package at $95 \%$ confidence interval which came out to be 985 .

The study sample was recruited by a two-stage cluster sampling technique. Intra-examiner reproducibility as determined using Kappa statistic was 0.85 . Clinical recordings of dental caries and malocclusion were done according to World Health Organization diagnostic criteria 1997. ${ }^{4}$ Periodontal health was assessed by Community Periodontal Index of Treatment Needs index. ${ }^{5}$ Malocclusion was assessed by dental aesthetic index. ${ }^{6}$

\section{Inclusion criteria}

School children (male and female) who have completed their 12 and 15 years of age.

Children present on the day of examination.

\section{Exclusion criteria}

Those children who refused to participate were excluded, and medically compromised children also were not included.

Also, the children undergoing orthodontic treatment were excluded for analysis of malocclusion.

A referral was forwarded to the parents of the children in need of dental care. At the conclusion of the survey, an oral health education session and tooth brushing demonstration was conducted in each classroom.

\section{Statistical analysis}

The data collected was analyzed by Statistical Package for Social Sciences (SPSS) package 13. The statistical tests used were $t$-test for continuous variables and Chi-square tests for categorical data. A level of $P \leq 0.05$ was considered statistically significant.

\section{RESULTS}

Of the total study population, $49.2 \%$ were in the 12 years age group and $50.8 \%$ were in the 15 years age group. Among the 12-year age group, there were $322(64.8 \%)$ males and 175 $(35.2 \%)$ females, while in the 15 -year age group there were $304(59.2 \%)$ males and $210(40.8 \%)$ females. Among the 12year age group, $46.1 \%$ of children were in government schools and $53.9 \%$ of children were in private schools, whereas in the age group of $1548.6 \%$ of the children were in government schools and $51.4 \%$ were in private schools.

A total of $100 \%$ of the children in private schools used toothbrush and tooth paste as compared with government schools (95.4\% used tooth brush and $93.6 \%$ used tooth paste) and the difference was statistically significant, $P<0.001$. The 
frequency of brushing twice a day was statistically higher in private schools than government schools.

Table 1: Mean DMFT in relation to Age and Gender

\begin{tabular}{|l|l|c|c|c|}
\hline AGE & SEX & MEAN DMFT & $\begin{array}{l}\text { STANDARD } \\
\text { DAVIATION }\end{array}$ & $\begin{array}{c}\text { P- } \\
\text { VALUE }\end{array}$ \\
\hline \multirow{3}{*}{$12 \mathrm{yrs}$} & Male & 0.537 & 1.330 & \\
\cline { 2 - 4 } & Female & 0.794 & 1.490 & \multirow{2}{*}{0.007} \\
\cline { 2 - 4 } & Total & 0.620 & 1.420 & \\
\hline \multirow{3}{*}{$15 \mathrm{yrs}$} & Male & 0.996 & 2.417 & \multirow{2}{*}{0.232} \\
\cline { 2 - 4 } & Female & 1.152 & 2.443 & \\
\cline { 2 - 4 } & Total & 1.060 & 2.930 & \\
\hline
\end{tabular}

The prevalence of dental caries at 12 years was $32.6 \%$ and at the age of 15 years it was $42.2 \%$. The prevalence of dental caries in government schools was $41.9 \%$ and in private schools it was $33.5 \%$ and the difference was statistically significant $(P<0.01)$.

The difference at two age groups was statistically significant $(P<0.001)$. At both the age groups, females showed higher mean DMFT as compared with the males and difference is statistically significant at 12 years. Subjects brushing their teeth once a day had higher mean DMFT as compared to those who brush twice a day and the difference is statistically significant at 12 years. (Table 1 )

Table 2 : Mean DMFT in relation to school

\begin{tabular}{|l|l|l|l|l|}
\hline AGE & SCHOOLS & DMFT & $\begin{array}{l}\text { STANDARD } \\
\text { DEVIATION }\end{array}$ & P VALUE \\
\hline \multirow{2}{*}{$\begin{array}{l}12 \\
\text { yrs }\end{array}$} & Government & 0.615 & 0.937 & \multirow{2}{*}{0.807} \\
\cline { 2 - 4 } & Private & 0.638 & 1.052 & \\
\hline \multirow{2}{*}{$\begin{array}{l}15 \\
\text { yrs }\end{array}$} & Government & 1.036 & 1.4432 & \multirow{2}{*}{0.712} \\
\cline { 2 - 4 } & Private & 1.083 & 1.462 & \\
\hline
\end{tabular}

At both ages, mean of decayed teeth was statistically higher in government schools as compared with private schools.At the age of 12 years, $50.1 \%$ of children required restorative and endodontic treatment and at the age of 15 years, $50.5 \%$ of children required restorative and endodontic treatment. The greatest need was for single surface restorations $(46.6 \%$ in 12 years and $47.6 \%$ in 15 years). The treatment need was higher in government schools at both the age groups but significantly higher at 12 years $(P<0.01)$. There was significant age difference regarding CPITN scores. The percent of children with healthy component of gingiva was higher at 15 years of age than 12 years. Higher percentage of children had calculus at 15 years as compared with 12 years. At both the age groups, higher percentages of children were having healthy sextants in private schools as compared with government schools. At 12 years, there was statistically higher percentage of children having calculus in government schools as compared with private.

A total of 48 children $(4.7 \%)$ had already undergone or were undergoing orthodontic treatment at the time of examination and these subjects were excluded for analyzing Dental Aesthetics Index (DAI) score. It was observed that a highly significant difference existed in the number of children seeking orthodontic treatment between government and private schools in favor of private schools $(P<0.001)$. The prevalence of malocclusion among the 12-year-old (58.1\%) was more as compared with that among the 15 -year-old $(53.5 \%)$

\section{DISCUSSION}

A cross-sectional study was carried out to assess the oral health status and treatment needs among school children in Nepal. The 12 and 15 age groups were chosen for this study, as these are global monitoring ages for dental caries for international comparisons and monitoring of disease trends. The present study sample consisted of school children from both public and private schools in order to have representation of children from all the social, economic, and cultural communities. At the age of 12 years, most of them (64\%) used to brush once a day which is in line with the findings of Joshi and Rajesh. ${ }^{7}$ In the present study, as the frequency of brushing increased prevalence of dental caries decreased. Similarly, with the increase in the frequency of brushing the prevalence and severity of periodontal diseases decreased. The reason being obvious, that there is significant correlation between plaque retention and gingival inflammation ${ }^{8}$ In the present study, it was observed that the prevalence of dental caries was higher at the age of 15 years $(42.2 \%)$ as compared with 12 years $(32.6 \%)$ which was also reported by Rodrigues and Damle. ${ }^{9,10}$ The reason for the higher prevalence of dental caries at 15 years as compared with 12 years is that caries being a continuous and cumulative process had obviously increased with a span of 3 years, as well as the number of teeth increases at the age of 15 years. The level of caries was higher in children attending government schools which is in line with the 
findings of Almeida et al., ${ }^{2}$ This may be due to lack of awareness, affordability, or underutilization of dental care facilities by the children in the government schools. So, further studies are needed to assess the various barriers for utilization of services.The mean filled teeth and missing due to other reasons were high in private schools which may be attributed to parents' attitude and dental awareness, of children in private schools which is reflected in the child's oral health maintenance. It was found that the children in private schools had higher proportion of healthy gingiva as compared with government schools which was also reported by Kumar et al. ${ }^{\prime \prime}$ This may be due to somewhat irregular oral hygiene practices in government school children.A total of $41.9 \%$ of the population at 12 years and $46.5 \%$ at 15 years presented no or minor malocclusion, indicating no or slight need for treatment which was also reported by Jenny et al., ${ }^{7}$ The severity levels of malocclusion assessed to be $35.2 \%$ definite malocclusion with elective need for orthodontic treatment at 12 years; and $15.6 \%$ at 15 years, and $17.0 \%$ severe malocclusion at 12 years and $15.6 \%$ at 15 years; and $5.9 \% \%$ handicapping malocclusion at 12 years and $6.4 \%$ at 15 years with mandatory orthodontic treatment need are similar to the results reported by Chi et al. ${ }^{3}$ and Jenny et al. ${ }^{7}$ There was no significant gender difference in DAI scores, though girls had a slightly lower score at 12 years age as compared with boys. This is comparable with the reports of Otuyemi et al. ${ }^{12}$ which did not find any significant sex differences in the mean DAI score of Nigerian children.The limitation of the present study was that the socioeconomic status of the subjects could not be assessed because the children could not be relied upon for this information and the.Collection of information from the school was not feasible

\section{CONCLUSION}

From the present study, it is concluded that the prevalence of dental caries at the age of 12 years was $32.6 \%$ and $42.2 \%$ at the age of 15 years. The mean DMFT was 0.06 at the age of 12 years and 1.02 at the age of 15 years, which means that caries prevalence in 12- and 15-year-old children in Nepal falls within the "very low" category as defined by the WHO. Dental caries was higher in government schools as compared with private schools. The maximum need was for one-surface restoration in both the age groups. Gingivitis was higher at the age of 12 years as compared with 15 years. The children in the private schools had higher proportion of healthy gingival as compared with government schools. The prevalence of malocclusion among the 12-year-old was more as compared with that among the 15 -year-old. As to improve the oral health of children in Nepal, the following recommendations are given:
- Oral health promotion through well-structured oral health education program can create positive change in awareness for special groups like school children

- Reinforcement of knowledge is necessary which can be done by incorporating chapters on oral health and oral hygiene in school textbooks. Also, the teachers training programs can ensure continuity of reinforcement

- Implementation of school dental health programs focusing on preventive programs like fluoride mouth rinse and tooth brushing programs

- Preventive services should be given high priority and needs to be started at an early age to target the primary dentition and future caries in permanent dentition

- Regular interval screening programs to assess the oral health and treatment needs of school children and provision of treatment as per the need.

\section{ACKNOWLEDGMENT}

The authors would like to thanks, Dr. Bindhanyanchal Yadav, Dr. Amrita Sapkota, Dr. Barun Kr. Jha, Dr. Diwash Adhikari without whose valuable input, this work would not have been possible.

\section{REFERENCE}

1. Addy M, Dummer PM, Hunter ML, Kingdon A, Shaw WC. The effect of toothbrushing frequency, toothbrushing hand, sex and social class on the incidence of plaque, gingivitis and pocketing in adolescents: A longitudinal cohort study. Community Dent Health 1990;7:237-47.

2. Almeida CM, Petersen PE, André SJ, Toscano. A Changing oral health status of 6- and 12-year-old schoolchildren in Portugal. Community Dent Health 2003;20:211-6.

3. Chi J, Johnson M, Harkness M. Age changes in orthodontic treatment need: A longitudinal study of 10- and 13-year-old children, using the Dental Aesthetic Index. Aust Orthod J 2000;16:150-6.

4. World Health Organization. Oral Health Surveys. Basic Methods. 4 thed. Geneva: 1997. p. 26-9.

5. Cutress TW, Ainamo J, Sardo-Infirri J. The community periodontal index of treatment needs (CPITN) procedure for population groups and individuals. Int Dent J 1987;37: $222-32$.

6. Dhar V, Jain A, Van Dyke TE, Kohli A. Prevalence of gingival diseases, malocclusion and fluorosis in school-going children of rural areas in Udaipur district. J Indian Soc Pedod Prev Dent 
2007;25:103-5.http://dx.doi.org/10.4103/0970-4388.33458

6. Jenny J, Cons NC. Establishing malocclusion severity levels on the Dental Aesthetic Index (DAI) scale. Aust Dent J 1996;41:436http://dx.doi.org/10.1111/j.1834-7819.1996.tb05654.x

7. Joshi N, Rajesh R. Prevalence of dental caries among school children in Kulasekharam village: A correlated prevalence survey. J Indian Soc Pedod Prev Dent 2005;23:13840.http://dx.doi.org/10.4103/0970-4388.16887

8. Kurt A, Rosenzwe G, Anselm L. Oral diseases in Yushiva students. JDent Res 1961;5:903-8.

9. Singh AA, Singh B, Kharbanda OP, Shukla DK, Goswami K, Gupta S. A study of dental caries in school children from Rural Haryana. JIndian Soc Pedod Prev Dent 1999;17:24-8.
10. Sogi G, Bhaskar DJ. Dental caries and oral hygiene status of 1314 year old school children of Davangere. J Indian Soc Pedod Prev Dent 2001;19:113-7.

11. Mahesh Kumar P, Joseph T, Varma RB, Jayanthi M. Oral health status of 5 years and 12 years school going children in Chennai city-An epidemiological study. J Indian Soc Pedod Prev Dent 2005;23:17-22.http://dx.doi.org/10.4103/0970-4388.16021

12. Otuyemi OD, Ogunyinka A, Dosumu O, Cons NC, Jenny J. Malocclusion and orthodontic treatment need of secondary school students in Nigeria according to the dental aesthetic index (DAI). Int Dent J 1999;49:203-10. http://dx.doi.org/10.1111/j.1875-595X.1999.tb00523.x 